INDO GLOBAL JOURNAL OF

PHARMACEUTICAL SCIENCES

ISSN 2249- 1023

\title{
Characterization of the Pigment Produced by a Psychrotolerant Strain of Penicillium sp. (MCC1061) isolated from Indian Himalayan Region
}

\author{
Neha Pandey ${ }^{1 *}$, Rahul Jain ${ }^{1}$, Anita Pandey ${ }^{1}$, Sushma Tamta ${ }^{2}$ \\ Biotechnological Applications, G B Pant National Institute of Himalayan Environment and Sustainable Development, Kosi-Katarmal, \\ Almora-263643, Uttarakhand, India
}

Department of Botany, DSB Campus, Kumaun University, Nanital-263001, Uttarakhand, India

Address for Correspondance: Neha Pandey, neha.pandey221@gmail.com

Keywords

Psychrotolerant;

Penicillium,

Pigment,

Carotenoid;

Antimicrobial

Activity .

\begin{abstract}
A psychrotolerant fungal strain (GBPI_P155), isolated from high altitude soil in Indian Himalayan Region, is characterized for its potential to produce natural pigment. The fungus was identified using morphological and molecular techniques. The fungus produced colonies having white margins with green sporulation releasing orange exudates on Potato Dextrose (PD) agar. Molecular identification based on ITS region (ITS1-5.8S-ITS2) sequencing showed maximum similarity of the fungus with Penicillium sp. The range of temperature and $\mathrm{pH}$ tolerance of the fungus was observed between 5 to $35^{\circ} \mathrm{C}$ (optimum $25^{\circ} \mathrm{C}$ ) and 214 (optimum $\mathrm{pH} 5-7$ ), respectively. The fungus was found to produce orange coloured water-insoluble pigment in PD broth starting from 5 days of incubation. The optimum temperature and $\mathrm{pH}$ for pigment production was found to be at $25{ }^{\circ} \mathrm{C}$ and $\mathrm{pH} \mathrm{5-7,} \mathrm{respectively,} \mathrm{in} \mathrm{PD} \mathrm{broth.} \mathrm{The} \mathrm{insoluble} \mathrm{pigment} \mathrm{precipitate}$ was extracted and solubilized in chloroform and characterized partially. UV/Vis spectrum of the chloroform extracted part showed $\lambda$ max at $495 \mathrm{~nm}$ with a shoulder peak at $530 \mathrm{~nm}$. Separation of chloroform extracted pigment was performed by thin layer chromatography (TLC) using different combinations of organic solvents. Best separation was achieved by hexane:acetone:toluene:ethanol (10:7:7:6) where two spots (orange and brown) having $\mathrm{Rf}$ values 0.89 and 0.79 , respectively, were observed. The extracted pigment also showed antimicrobial activity against Gram positive bacteria (Bacillus subtilis and B. megaterium). Based on the preliminary analysis of extracted pigment, it appears to belong to the carotenoid group. Further analysis of the pigment using advanced techniques is in progress. (C) 2016 iGlobal Research and Publishing Foundation. All rights reserved.
\end{abstract}

Conference Proceedings: International Conference on Advances in Plant and Microbial Biotechnology (PMB2017); JIIT, Noida: February 02-04, 2017

Indo Global Journal of Pharmaceutical Sciences( ISSN 22491023 ; CODEN- IGJPAI; NLM ID: 101610675) indexed and abstracted in EMBASE(Elsevier), SCIRUS(Elsevier),CABI, CAB Abstracts, Chemical Abstract Services(CAS), American Chemical Society(ACS), Index Copernicus, EBSCO, DOAJ, Google Scholar and many more. For further details, visit http://iglobaljournal.com 